\title{
ReSEARCHARTICLE
}

\section{Variation in arjunolic acid in bark of Terminalia arjuna from different geographical locations of India using high performance liquid chromatography}

Sonu Bharti, Sandeep Kumar, Neelu Singh and Shamim Akhtar Ansari

\begin{abstract}
SUMMARY
Major active ingredient of Terminalia arjuna bark, a triterpenoid saponins -arjunolic acid was determined in fifty-one accessions of different geographical locations from seven different states i.e. Madhya Pradesh, Orissa, Uttar Pradesh, Maharashtra, Jharkhand, Uttrakhand and Andhra Pradesh of India.Arjunolic acid was extracted from bark samples with the help of microwave assisted method and quantified by High Performance Liquid Chromatography (HPLC). A significant variation in arjunolic acid content was observed in bark from different regions. The quantity of arjunolic acid varied 0.01$0.29 \mu \mathrm{g} / \mathrm{mg}$, maximum quantity was observed in Accession- UKDDLP belongs to Uttrakhand, Western Himalayan region. The eastern plateau and hill region of the state produced the lowest amount, whereas the western Himalayan regions zone of the state had higher yields. The populations with high arjunolic acid content can be utilized for mass multiplication and genetic improvement.
\end{abstract}

Key Words : Terminalia arjuna, Bark, Arjunolic acid, Geographical regions, HPLC

How to cite this article : Bharti, Sonu, Kumar, Sandeep, Singh, Neelu and Ansari, Shamim Akhtar (2021). Variation in arjunolic acid in bark of terminalia arjuna from different geographical locations of India using high performance liquid chromatography. Internat. J. Plant Sci., 16 (1): 39-45, DOI: 10.15740/HAS/IJPS/16.1/39-45, Copyright@ 2021: Hind Agri-Horticultural Society.

Article chronicle : Received : 11.10.2020; Revised : 10.11.2020; Accepted : 11.12.2020

\section{MEMBERS OF THE RESEARCH FORUM}

Author to be contacted :

Sonu Bharti, Department of Life Science, National Institute of

Technology, Rourke4la (Odisha) India

Email : sonugpb@rediffmail.com

Address of the Co-authors:

Sandeep Kumar, Neelu Singh and Shamim Akhtar Ansari, Genetics

and Plant Propagation Division, Torpical Forest Research Institute,

Jabalpur (M.P.) India 